\title{
Social class in asthma and allergic rhinitis: a national cohort study over three decades
}

\author{
L. Bråbäck*, A. Hjern\#, ${ }^{\#}$ and F. Rasmussen ${ }^{+}$
}

\author{
ABSTRACT: The aim of this study was to assess whether the association with social class \\ differed between allergic rhinitis and asthma and whether these associations have changed over \\ time.
}

The Swedish Military Service Conscription Register was linked to two other national registers for 1,247,038 male conscripts in successive cohorts born between 1952 and 1977.

The percentage of asthma cases associated with allergic rhinitis was $15 \%$ in the oldest cohort and $44 \%$ in the youngest cohort. Low socio-economic status (SES) was associated with an increased risk (assessed as odds ratio) of asthma without allergic rhinitis $(1.14,95 \%$ confidence interval $(\mathrm{Cl}) 1.11-1.17)$ but a slightly reduced risk of asthma with allergic rhinitis $(0.96,95 \% \mathrm{Cl}$ $0.93-1.00$ ). The risk of allergic rhinitis was $0.84,95 \% \mathrm{Cl} 0.82-0.85$. A positive interaction between SES and year of birth occurred in all three conditions. Low SES was related to a reduced risk of asthma with allergic rhinitis in the earliest cohort $(0.72,95 \% \mathrm{Cl} 0.53-0.82)$ but a slightly increased risk in the most recent cohort $(1.07,95 \% \mathrm{Cl} 1.01-1.14)$.

In conclusion, the role of social class has changed over time. The steepest increase in asthma and allergic rhinitis occurred in conscripts with a low socio-economic status.

KEYWORDS: Asthma-allergic rhinitis, asthma epidemiology, birth cohort, socio-economic status, time trend

$\mathbf{T}$ he increased prevalence of hay fever in the UK during the 19th century was linked to industrialisation and started in the affluent classes [1]. The association between social advantage and hay fever remained in the 20th century [2] and was also demonstrated in studies based on objective tests [3-5]. In particular, socioeconomic status (SES) early in life appeared to be important. Low SES in early childhood provided protection from atopic sensitisation at the age of 33 yrs in a British birth cohort from 1958 [5]. High social class and educational level was a risk factor for atopy in Eastern Germany [4], although atopic diseases were more likely in the western, more affluent, part of Germany [6].

Low SES has been related to an increase in the severity of asthma but the association between social class and the occurrence of asthma is less clear $[7,8]$. Conflicting evidence regarding the relationship between social class and asthma could be related to geographical or temporal variations. Furthermore, inconsistent findings may arise from studies that do not distinguish between atopic and nonatopic asthma, since they are separate entities with at least partly different backgrounds [9]. The rise in childhood asthma has comprised both atopic and nonatopic asthma.
It has been argued that the role of atopy has been overemphasised, as $<50 \%$ of all asthma is atopic [10].

Substantial changes in the standard of living have taken place in Sweden over the last $40-50$ yrs. The current authors have previously demonstrated that the increase in asthma among young males in Sweden accelerated in cohorts born after 1960 [11]. In the current survey, the authors have investigated the prevalence of allergic rhinitis and asthma (with and without allergic rhinitis) in Swedish conscripts by year of birth and social class. It has been evaluated whether the association with social class differed between allergic rhinitis and asthma with and without allergic rhinitis and whether these associations have changed over three decades.

\section{MATERIALS AND METHODS}

Sweden has a long tradition of national registers with high-quality data relating to socio-economic and health indicators for the entire Swedish population. The key to these registers is the unique personal identification number for each Swedish citizen. In this study, the current authors used the Swedish Military Service Conscription Register (MSCR; 1968-1996), the Register of the
AFFILIATIONS

*Dept of Public Health and Research, Sundsvall Hospital,

\#Unit of Paediatrics, Dept of Women's and Children's Health, Uppsala University,

"Centre for Epidemiology, Swedish National Board of Health and Welfare, and

${ }^{+}$Child and Adolescent Public Health Epidemiology Group, Dept of Public Health Sciences, Karolinska Institutet, Stockholm, Sweden.

CORRESPONDENCE

$F$. Rasmussen

Child and Adolescent Public Health Epidemiology Group

Dept of Public Health Sciences Karolinska Institutet

SE-171 76 Stockholm

Sweden

Fax: 46851776529

E-mail: finn.rasmussen@phs.ki.se

Received:

February 252005

Accepted after revision:

July 072005 
Total Population (RTP; 1967-1996) and the Population and Housing Censuses (PHC; 1970, 1975, 1980, 1985, 1990). Statistics Sweden maintains the Multi-Generation Register with records of the unique personal identification (ID) numbers of the mothers and fathers of almost all the individuals born after 1932, who were alive and resident in Sweden in 1961. The parents of the study subjects were identified by record linkage to this register.

\section{Study population}

All Swedish-born males born between 1952 and 1977 were identified at age $17 \mathrm{yrs}$, using their unique personal ID number, in the RTP. All the individuals recorded as living in Sweden are included in these registers. Of the young males born in 1952-1959 and 1961-1977 who were thus identified, the $90.9 \%(1,239,705)$ who were recorded in the MSCR as having participated in the military service conscription examination at aged 17-20 yrs were included in the study population. Of the cohort born in 1960 , only $14.6 \%(7,333)$ participated in a military service conscription examination due to administrative changes to the entire conscription system in Sweden. These subjects were added to the study population.

The Swedish military service conscription examination is required by law. Foreign citizenship or a severe chronic medical condition or handicap documented in a medical certificate are the only reasons that are accepted for nonparticipation according to Swedish law.

\section{Variables in the study}

Allergic disorders

The examination of the conscripts consisted of a health questionnaire, a personal interview by a medical doctor and a comprehensive physical and psychological examination that includes a physical exercise test. The health questionnaire is sent to the conscripts prior to the examination and contains specific questions about itchy or watery eyes, congested nose/ allergic rhinitis, wheezing, asthma and eczema. The examining doctor makes a registration of diagnoses on a practical clinical basis, with the emphasis on conditions that may affect the young male's performance in the military service. The diagnostic codes were based on the International Classification of Diseases (ICD-8 and ICD-9) in 1968-1986: 493 (asthma) and 477 (allergic rhinitis). The diagnoses were set by the doctor after having seen the answers to the questionnaire and investigated the conscript. The diagnostic procedure has changed very little over the years, with the exception of the health questionnaire, which has been changed several times.

The diagnostic category of asthma was divided into two parts: asthma without allergic rhinitis (as a proxy to nonallergic asthma) and asthma with allergic rhinitis (as a proxy to allergic asthma).

\section{Socio-economic status}

SES was defined according to the categorisation of the head of the household in the PHC nearest to the military conscription examination made by Statistics Sweden [12]. The categories were based on occupation but also took account of the educational level of occupation, the type of production and the position at work of the head of the household. Two different classifications were used during the study period, one in the PHCs from 1970 and 1975 and another in 1980, 1985 and 1990. These classifications only overlapped in the broad categories of white collar/blue collar, which forced the use of this limited dichotomous variable (high/low).

\section{Socio-demographic confounders}

A number of available variables that have been shown to be important determinants of allergic disorders in previous studies of Swedish conscripts [11-14] were added to the analysis as possible confounders.

Information from the PHC nearest in time to the military conscription and the geographical location of the home in the RTP for conscripts aged 17 yrs were used to create a dichotomous rural/urban variable. In the PHC, urban is defined as a home located in a settlement with $\geqslant 200$ inhabitants. Parental occupation from the PHC nearest in time to the military conscription was used to create a dichotomous "farmer" variable. County of residence was identified in the RTP at aged 17 yrs and classified into six categories, one for southern Sweden and five for northern Sweden. Maternal age at the birth of the conscript was calculated using information relating to the year of birth of the mother and the conscript from the RTP. Variables of family size and overcrowding (defined as more than two people per room excluding the kitchen and one more room) were created using data from the PHC nearest to the conscription examination. A variable of being the first-born male in the family, as a proxy to first-born child in the absence of sisters, was created by linkage to the multi-generation register of the conscripts in the study.

\section{Body mass index}

Weight and height measurements at the military conscription examination were used to calculate body mass index (BMI). Four BMI categories were created according to WHO criteria [15]: $\geqslant 30.00$ (obese), 25.00-29.99 (overweight), 18.50-24.99 (reference) and $\leqslant 18.49$ (low).

\section{Statistical analyses}

Asthma with allergic rhinitis, asthma without allergic rhinitis and allergic rhinitis were used as dependent variables in logistic regression models. These models included a dichotomous low/high SES variable, dichotomous confounders and a four-category BMI variable as defined above. Missing was included in the models as a third category for confounders and SES. Year of birth was entered as a continuous variable in all the models. Logistic regression models that contained all the variables described above were used to calculate the interaction of time (year of birth) with other independent variables. The test-based method was used to calculate $95 \%$ confidence intervals (CI).

\section{Ethical considerations}

The study was approved by the Ethics Committee at the Karolinska Institutet in Stockholm.

\section{RESULTS}

The study comprised 1,247,038 male conscripts. In all, $32.5 \%$ were classified as low SES, $40.2 \%$ as high SES, while $27.4 \%$ could not be classified. Additional socio-demographic characteristics have been presented in a previous paper [11]. 
The prevalence of asthma and allergic rhinitis increased continuously with year of birth during the entire study period. In conscripts born in 1952-1956, the prevalence rates for asthma without allergic rhinitis, asthma with allergic rhinitis and allergic rhinitis were $1.7 \%, 0.3 \%$ and $4.9 \%$, respectively. The corresponding prevalence rates in conscripts born in 19721977 were $3.1 \%, 2.4 \%$ and $16.4 \%$ respectively. As a result, $15 \%$ of all asthma cases had allergic rhinitis in the earliest birth cohort compared with $44 \%$ in the most recent cohort.

Low SES was associated with an increased risk of asthma without allergic rhinitis (odds ratio (OR) 1.14; 95\% CI 1.111.17), but a reduced risk of asthma with allergic rhinitis, (OR 0.96; 95\% CI 0.93-1.00), and allergic rhinitis (OR 0.84; 95\% CI $0.82-0.85)$, after multivariate analyses of the entire sample. However, the steepest increase in asthma and allergic rhinitis occurred in conscripts with a low SES (fig. 1) and the ORs for asthma and allergic rhinitis changed over time (table 1). The exclusion of overcrowding from the logistic model had marginal effects on the ORs for social class in cohorts born before 1962 and no effect at all in cohorts born after 1961. The multivariate analyses confirmed a positive interaction between low SES and year of birth in all three conditions $(\mathrm{p}<0.001$; data not shown). The interaction effect was similar for the three decades in the study for all three conditions.

\section{DISCUSSION}

The linkage of national registers in Sweden at an individual level has enabled the current authors to carry out this epidemiological study of $>1.2$ million conscripts in successive birth cohorts born between 1952 and 1977. A two-fold increase in asthma without allergic rhinitis and a three- to four-fold increase in allergic rhinitis and asthma associated with allergic rhinitis was found over a period of less than three decades. An increase in asthma and allergic rhinitis was demonstrated both in high and in low social class, but the steepest increase occurred in conscripts with low SES. Low social class was associated with an increased risk of asthma without allergic rhinitis in all birth cohorts, but it only contributed to an increased risk of asthma with allergic rhinitis in the most recent birth cohorts. A strong inverse relationship between low SES and allergic rhinitis was revealed in conscripts born in the 1950s. The association between low social class and allergic rhinitis decreased over time and the association was fairly weak in conscripts born after 1970.

The declining association between allergic rhinitis and social class in recent Swedish birth cohorts suggests that lifestyles promoting allergic diseases have been adopted in all social classes. No difference will be seen between cases and controls in a society in which all the individuals are exposed [16]. The current authors cannot wholly exclude the possibility that differential misclassification with an increasing awareness of allergic diseases in lower social classes may contribute to the changes in time trends. However, the findings are consistent with those relating to British birth cohorts from 1958 and 1970, showing a more pronounced association between hay fever and social class in the early cohort [2].

The association between social class and asthma has been conflicting. An American study showed a positive association between increasing education level and asthma with hay fever
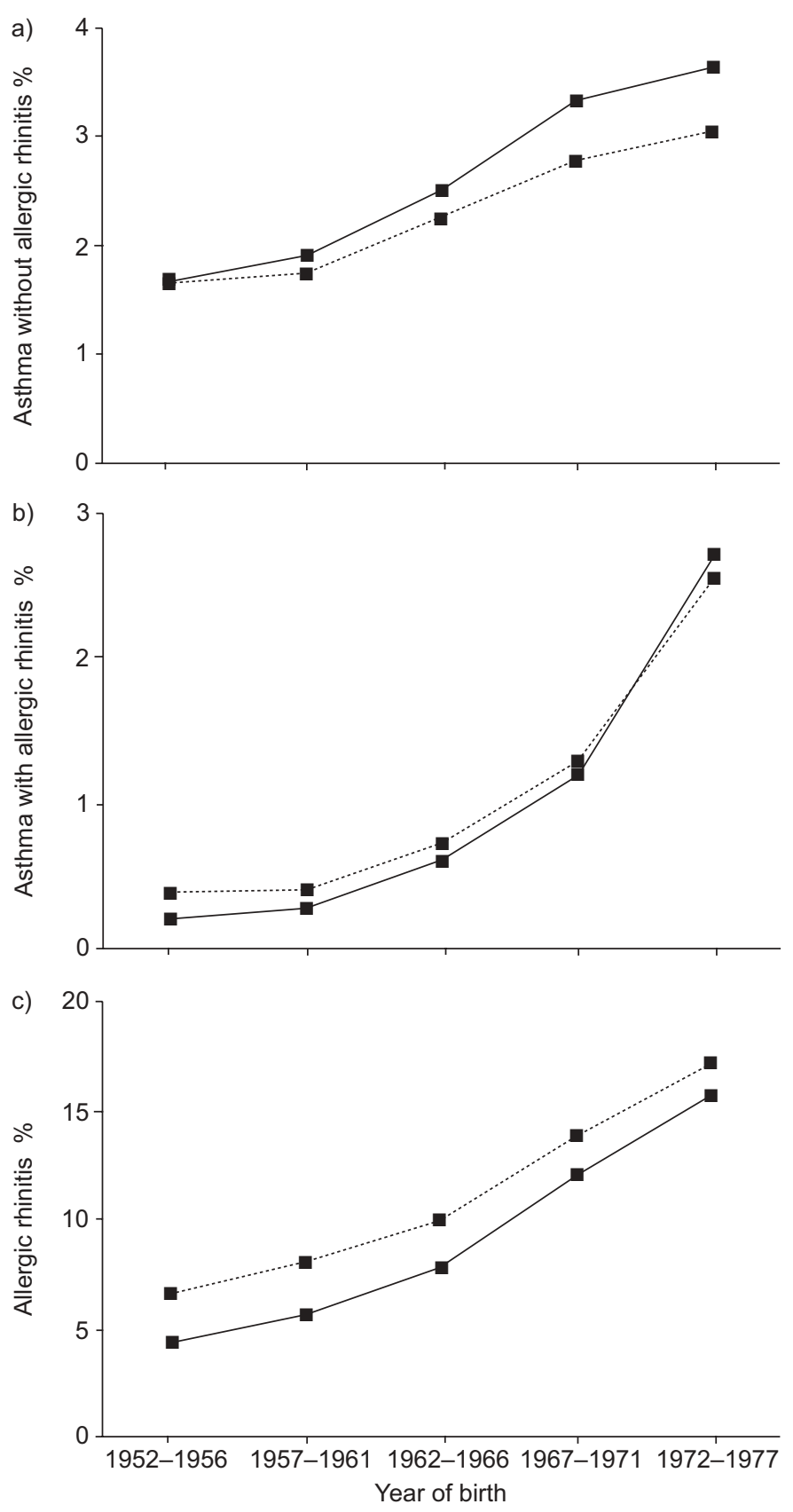

FIGURE 1. Asthma and allergic rhinitis in Swedish male conscripts by year of birth and social class (-----: high socio-economic status; _- : low socio-economic status). a) Asthma without allergic rhinitis; b) asthma with allergic rhinitis; c) allergic rhinitis.

but a negative association between education level and asthma without hay fever [17]. Similarly, a recent British study revealed that social class had differential effects on atopic and nonatopic asthma [9]. In contrast, poverty at both an individual and an area level was associated with an increased risk of asthma regardless of sensitisation in the large European Community Respiratory Health Survey comprising young adults from 15 countries [18]. The current Swedish survey suggests that the role of SES in asthma has changed over time and such changes may explain the conflicting findings in other 


\section{TABLE 1 The association between social class, asthma and allergic rhinitis}

1952-1961

$1.17(1.11-1.24)$
$1.05(0.99-1.11)$
1

$0.86(0.74-0.99)$

$0.72(0.53-0.82)$

$0.84(0.83-0.96)$

$0.79(0.77-0.81)$

1

1962-1971

1.09 (1.05-1.14)

$1.17(1.12-1.22)$

1

$0.90(0.83-0.97)$

$0.92(0.86-0.99)$

1

$0.89(0.87-0.91)$

$0.83(0.82-0.86)$

1

1972-1977

1.13 (1.06-1.22)

$1.20(1.14-1.26)$

1

1.05 (0.97-1.13)

1.07 (1.01-1.14)

1

$0.91(0.88-0.93)$

$0.92(0.90-0.94)$

1

Data presented as adjusted odds ratio (95\% confidence interval) after multivariate analyses of different birth cohorts born in 1952-1961, 1962-1971 and 1972-1977 and adjusting for body mass index, county of residence, rural living, overcrowding and being the first-born male. SES: socio-economic status.

studies. The differences between asthma with allergic rhinitis and asthma without allergic rhinitis in relation to low SES tend to disappear in recent cohorts. A low SES implied a reduced risk of allergic asthma in the oldest birth cohorts but an increased risk in the youngest cohort. Moreover, the steepest increase in asthma with allergic rhinitis and asthma without allergic rhinitis has occurred in individuals from less advantaged social classes. This is in agreement with the high prevalence of allergic asthma [19] and sensitivity to inhalant allergens [20] in poor inner-city areas in the USA. A disproportionate increase in asthma in lower social classes has also been observed in British schoolchildren born after 1983 [21]. An ongoing Swedish birth cohort study recently demonstrated an increased risk of asthma and allergic sensitisation in children with low SES aged 4 yrs [22].

Housing standard has improved in Sweden since the 1950s, particularly in low social classes. Domestic crowding is closely associated with social class but adjustment for overcrowding had only marginal effects on the ORs for social class in the multivariate analyses. However, poor housing conditions also include, for example, psychosocial stress and increased exposure to dampness and mould, which may contribute to an increased risk of asthma in individuals with low SES.

Differences in food habits often explain socio-economic differences in health. Intake of fruit and unsaturated fat has been associated with an increased risk of atopy and asthma [23]. Consumption of fruit is lower and consumption of saturated fat higher in individuals with low SES [24, 25]. Obesity is linked both to asthma and to low SES [14] but the increased risk of asthma in conscripts with low SES in the current study persisted after adjustment for BMI.

A register-based study is limited by the array of variables available for statistical analyses. In this study, information on atopic heredity and exposure to tobacco smoke, for example, would have been most valuable. Genes and environment interact and smoking may contribute to the increased risk of asthma in conscripts with a low SES [26]. Smoking is more likely in nonaffluent groups but smoking has been declining in
Sweden since 1980, both in males and in females and in all social classes [27]. However, reports from other countries in Western Europe indicate that the differences in smoking habits between the social classes have increased over time. Smoking in Norway was more common in males with a high income and less common in males with a low income in the 1950s. A switch-over occurred around 1975 and smoking was more common in low income males in 1990 but at a lower level in comparison with the 1950s [28].

The proportion of the Swedish population that is categorised as low SES has decreased over time, as manual jobs have been replaced by white-collar jobs on the Swedish labour market. This may have caused a steeper social gradient in recent years, which may explain some or all of the steeper time trend for low SES compared with high SES for nonatopic asthma. However, this is not the case for the atopic disorders, where the social gradient is reversed.

The ORs for social class in the current study are fairly low. There is less income inequality in Sweden and other Scandinavian countries than there is in the UK, for example [29]. Moreover, changes in the classification of SES in the Swedish Population and Housing Censuses have restricted the classification of social class to blue- and white-collar workers in the current study. Even if the sensitivity and specificity of exposure and outcome variables in this register-based study may be lower than those in smaller studies based on data sets created ad hoc, the misclassification bias is nondifferential. It is therefore likely that the associations between social class and disease outcome are underestimated in the present study. The clear-cut associations between social class and asthma with and without allergic rhinitis seen in table 1 may thus be underestimates of the true associations.

The current study has further limitations. In the statistical analyses, the current authors have distinguished between asthma with allergic rhinitis and asthma without allergic rhinitis. Asthma without allergic rhinitis does not exclude atopy, but asthma with and without allergic rhinitis could be used as a reasonably good proxy for allergic and nonallergic 
asthma. The diagnoses of asthma or allergic rhinitis were always made by a doctor and a previous validation suggested that the accuracy of the diagnosis at the conscript examination was fairly good. Approximately $80 \%$ of all cases of asthma and allergic rhinits were detected at the conscript examinations [12]. Misclassification is likely to be nondifferential and reduce the associations. Over the years the questions related to allergic disorders in the health questionnaire became somewhat more specific. However, it does not seem probable that this affected the prevalence rates in any major way since the diagnosis was based primarily on follow-up questions made by physicians during the health examination.

To summarise, Sweden is a westernised country with a high standard of living. A substantial increase in the percentage of asthma cases associated with allergic rhinitis has occurred over a period of three decades. However, the role of social class has changed and the rate of the increasing prevalence of asthma and allergic rhinitis was more rapid in conscripts with a low socio-economic status.

\section{REFERENCES}

1 Emanuel MB. Hay fever, a post industrial revolution epidemic: a history of its growth during the 19th century. Clin Allergy 1988; 18: 295-304.

2 Butland BK, Strachan DP, Lewis S, Bynner J, Butler N, Britton J. Investigation into the increase in hay fever and eczema at age 16 observed between the 1958 and 1970 British birth cohorts. BMJ 1997; 315: 717-721.

3 Gergen PJ, Turkeltaub PC, Kovar MG. The prevalence of allergic skin test reactivity to eight common aeroallergens in the U.S. population: results from the second National Health and Nutrition Examination Survey. J Allergy Clin Immunol 1987; 80: 669-679.

4 Heinrich J, Popescu MA, Wjst M, Goldstein IF, Wichmann HE. Atopy in children and parental social class. Am J Public Health 1998; 88: 1319-1324.

5 Strachan DP, Harkins LS, Johnston ID, Anderson HR. Childhood antecedents of allergic sensitization in young British adults. J Allergy Clin Immunol 1997; 99: 6-12.

6 von Mutius E, Martinez FD, Fritzsch C, Nicolai T, Roell G, Thiemann HH. Prevalence of asthma and atopy in two areas of West and East Germany. Am J Respir Crit Care Med 1994; 149: 358-364.

7 Rona RJ. Asthma and poverty. Thorax 2000; 55: 239-244.

8 Mielck A, Reitmeir P, Wjst M. Severity of childhood asthma by socioeconomic status. Int J Epidemiol 1996; 25: 388-393.

9 Court CS, Cook DG, Strachan DP. Comparative epidemiology of atopic and non-atopic wheeze and diagnosed asthma in a national sample of English adults. Thorax 2002; 57: 951-957.

10 Pearce N, Pekkanen J, Beasley R. How much asthma is really attributable to atopy? Thorax 1999; 54: 268-272.

11 Bråbäck L, Hjern A, Rasmussen F. Trends in asthma, allergic rhinitis and eczema among Swedish conscripts from farming and non-farming environments. A nationwide study over three decades. Clin Exp Allergy 2004; 34: 38-43.

12 Åberg N. Asthma and allergic rhinitis in Swedish conscripts. Clin Exp Allergy 1989; 19: 59-63.
13 Bråbäck L, Hedberg A. Perinatal risk factors for atopic disease in conscripts. Clin Exp Allergy 1998; 28: 936-942.

14 Bråbäck L, Hjern A, Rasmussen F. Body mass index, asthma and allergic rhinoconjunctivitis in Swedish conscripts - a national cohort study over three decades. Respiratory Medicine 2005; 99: 1010-1014.

15 World Health Organisation. Obesity. Preventing and managing the global epidemic. Report of a WHO Consultation on obesity. Geneva, World Health Organization, 1998.

16 Rose G. Sick individuals and sick populations. Int J Epidemiol 1985; 14: 32-38.

17 Chen JT, Krieger N, Van Den Eeden SK, Quesenberry CP. Different slopes for different folks: socioeconomic and racial/ethnic disparities in asthma and hay fever among 173,859 U.S. men and women. Environ Health Perspect 2002; 110: Suppl. 2, 211-216.

18 Basagana X, Sunyer J, Kogevinas $M$, et al. Socioeconomic status and asthma prevalence in young adults: the European Community Respiratory Health Survey. Am J Epidemiol 2004; 160: 178-188.

19 Matricardi PM, Bouygue GR, Tripodi S. Inner-city asthma and the hygiene hypothesis. Ann Allergy Asthma Immunol 2002; 89: 69-74.

20 Lewis SA, Weiss ST, Platts-Mills TA, Syring M, Gold DR. Association of specific allergen sensitization with socioeconomic factors and allergic disease in a population of Boston women. J Allergy Clin Immunol 2001; 107: 615-622.

21 Rona RJ, Hughes JM, Chinn S. Association between asthma and family size between 1977 and 1994. J Epidemiol Community Health 1999; 53: 15-19.

22 Almqvist C, Pershagen G, Wickman M. Low socioeconomic status as a risk factor for asthma, rhinitis and sensitization at 4 years in a birth cohort. Clin Exp Allergy 2005; 35: 612-618.

23 Devereux G, Seaton A. Diet as a risk factor for atopy and asthma. J Allergy Clin Immunol 2005; 115: 1109-1111.

24 Hulshof KF, Brussaard JH, Kruizinga AG, Telman J, Lowik MR. Socio-economic status, dietary intake and $10 \mathrm{yr}$ trends: the Dutch National Food Consumption Survey. Eur J Clin Nutr 2003; 57: 128-117.

25 Irala-Estevez JD, Groth M, Johansson L, Oltersdorf U, Prattala R, Martinez-Gonzalez MA. A systematic review of socio-economic differences in food habits in Europe: consumption of fruit and vegetables. Eur J Clin Nutr 2000; 54: 706-774.

26 Strachan DP, Butland BK, Anderson HR. Incidence and prognosis of asthma and wheezing illness from early childhood to age 33 in a national British cohort. BMJ 1996; 312: 1195-1119.

27 Atkinson $\mathrm{AB}$. Income distribution in Europe and the United States. Oxford Review of Economic Policy 1996; 12: 15-28.

28 Lund KE, Roenneberg A, Hafstad A. The social and demographic diffusion of the tobacco epidemic in Norway. In: Slama K, ed. Tobacco and Health. New York, Plenum Press, 1995; pp. 565-551.

29 Atkinson A, Rainwater L, Smeding T. Income distribution in OECD countries: evidence from the Luxembourg Income Study. Paris, OECD, 1995; www.lis.ceps.lu/. Date updated: 6 October 2004. Date accessed: 17 July 2005. 